\title{
Territorios de lo moderno: la recepción de la obra de Emilio Pettoruti y Martín Noel en la Revista de Arte $^{1}$
}

\section{Territory of Modern: The Reception of the Work of Emilio Pettoruti and Martín Noel in the Revista de Arte}

\author{
Rodrigo Vera Manríquez \\ Universidad de Chile \\ veramanriquez@gmail.com \\ Claudio Guerrero Urquiza \\ Universidad Diego Portales \\ cguerrerourquiza@gmail.com
}

\section{Resumen}

El texto expone diversos modos de articular las nociones de tradición y modernidad en el arte y la arquitectura según los contenidos aparecidos en el número 11 (1936) de la Revista de Arte (Facultad de Bellas Artes de la Universidad de Chile) dedicado a Argentina. El análisis se centra en dos artículos. El primero: "Emilio Pettoruti: brújula de la pintura argentina", de Leonardo Estarico. El segundo: “América y la nueva arquitectura”, de Martín Noel. Mientras Estarico postula los conceptos de forma y de plástica como territorios universales, Noel establece al continente americano como fuente para el arte y la arquitectura local.

Palabras clave: Arte, arquitectura, americanismo, Argentina, Chile.

\section{Abstract}

This paper presents different ways to articulate the notions of tradition and modernity in art and architecture according to the contents of number 11 (1936) of Revista de Arte (Academy of Fine Arts at Universidad de Chile) dedicated to Argentina. The analysis focuses on two articles. The first one: "Emilio Pettoruti: brújula de la pintura argentina", by Leonardo Estarico. The second one: "America y la nueva arquitectura" by Martin Noel. Estarico proposes the concepts of form and plastic as universal territories, while Noel establishes the American continent as an essential source for local art and architecture.

Keywords: Art, architecture, americanism, Argentina, Chile.

1 Este artículo forma del proyecto Fondecyt Iniciación 11170292 "El binomio conceptual arte y técnica en las publicaciones periódicas artísticas e industriales en Chile (1929-1939): la introducción de una idea de diseño moderno", cuyo Investigador Responsable es el Dr. Rodrigo Vera Manríquez. 


\section{Introducción: la revista como soporte}

Entre los años 1934 y 1939, la recién creada Facultad de Bellas Artes de la Universidad de Chile editó la Revista de Arte, ${ }^{2}$ una publicación bimestral de divulgación. A través de sus páginas, reprodujo una serie de posturas en torno al lugar del arte y la cultura ante las profundas transformaciones económicas, sociales y políticas de la década del 30, las reformas a la educación artística ocurridas en el gobierno de Ibáñez del Campo (1927-1931), la crisis mundial de 1929, la recepción de lenguajes artísticos foráneos y el desarrollo de la plástica local. Fueron 21 números que contenían ensayos, artículos, noticias nacionales y extranjeras, semblanzas y reseñas de libros en los ámbitos de la pintura, la escultura, el grabado, la danza, la música, la fotografía y el cine, entre otros. Además, la revista dedicó un particular espacio a la arquitectura, que se manifestó más bien desde actores gremiales que universitarios; vale decir, fueron la Asociación de Arquitectos de Chile y el Instituto Nacional de Urbanismo las instituciones que abordaron esta disciplina al interior de la revista, con muy escasa participación de académicos.

La Facultad de Bellas Artes de la Universidad de Chile venía a integrar definitivamente bajo el alero universitario a la pintura, la escultura, las artes aplicadas, la música y la danza. La revista cumplía con informar y promocionar las actividades institucionales, luego de un complejo proceso de reestructuración de la educación artística chilena, que consideró el cierre de algunas instituciones y la apertura de otras ${ }^{3}$ en un contexto político muy convulsionado.

Es por ello que la publicación de la Revista de Arte consolidaba la nueva estructura académica de la Universidad de Chile en general, y de la enseñanza artística en particular, logrando editar un órgano de divulgación a cinco años de la fundación de la Facultad.

En este artículo se presentará y analizará la edición número 11 de la revista, lanzada en 1936 y dedicada al arte en Argentina. En particular, el análisis se centra en dos artículos relativos a la pintura y a la arquitectura que proponen dispares visiones de lo moderno a través de referencias y metáforas territoriales. El primero de ellos, de autoría de Leonardo Estarico, se titula "Emilio Pettoruti: brújula de la pintura argentina”. El carácter orientador y fronterizo que se le atribuye al pintor nos anuncia la hipótesis vanguardista de Estarico. El segundo, se trata de un artículo escrito por el arquitecto argentino Martín Noel, que lleva por nombre "América y la nueva arquitectura". Este texto expresa un sentido más americanista, pues reivindica un sustento cultural, territorial y simbólico ante el corte total con el pasado que propondría la arquitectura funcionalista. Por cierto, el objetivo es analizar las direcciones y tensiones

\footnotetext{
2 La revista tuvo una segunda época, esta vez dependiente del Instituto de Extensión de Artes Plásticas, entre 1955 y 1962.

3 Para más detalles, pueden consultarse los estudios de Berríos, Cancino y Santibañez (2012) y Castillo (2010).
} 
que despliegan las ideas de tradición y modernidad en relación con el territorio, para comprender algunas de las posibilidades de sentido que estos términos poseían entonces en Chile y Argentina, por medio de la disección de estos dos artículos insertos en un medio de difusión nacional que, para este número, tenía la intención de dar a conocer algunos aspectos generales del arte argentino. Dentro de esa generalidad aparecen los puntos de encuentro y desencuentro en torno a lo moderno esgrimidos por Estarico y Noel que permiten establecer el contrapunto.

Se comenzará presentando un contexto general de la situación cultural del periodo de entreguerras para posteriormente acercar el análisis a la revista en cuestión. Luego se procederá al examen de ambos textos para concluir relevando aspectos disímiles y puntos de confluencia extraídos del estudio de la discursividad acerca de Pettoruti y los argumentos de Noel sobre la arquitectura en Latinoamérica.

\section{Chile, Argentina y la coyuntura de la década del 30}

Chile y Argentina vivían en la década del 30 momentos relativamente análogos en sus desarrollos políticos y sociales que las gravísimas consecuencias de la crisis económica mundial iniciada el año 1929 tendió a sincronizar. Tras la celebración del Centenario en 1910, ambos países habían iniciado procesos de democratización caracterizados por el acceso al poder de las clases medias y obreras, a través del avance del sufragio universal y del triunfo de candidatos que aspiraban a representar a los sectores populares. Es el caso de Hipólito Yrigoyen en Argentina y de Arturo Alessandri Palma en Chile, al que sigue la dictadura modernizadora y nacionalpopulista de Carlos Ibáñez del Campo. En un proceso de reacción, la mayor parte de la década del 30 estuvo gobernada en ambos países por coaliciones conservadoras. Sin embargo, la emergencia de la clase media y de importantes masas de trabajadores a la vida pública era un proceso irreversible, lo que explica la posterior llegada al poder de Juan Domingo Perón y Pedro Aguirre Cerda, con quienes se inicia un nuevo ciclo de reformas nacionalpopulistas en Argentina y Chile, respectivamente. En un horizonte mundial en que se alzaban los totalitarismos de izquierda y derecha, esta emergencia de las masas implicó necesariamente importantes transformaciones culturales.

La rearticulación del horizonte político mundial y local tuvo como dato insoslayable el desarrollo de la vanguardia artística y del movimiento moderno en arquitectura. Hacia la década del 30, la primera tendía a bajar la radicalidad que había caracterizado los años posteriores a la Primera Guerra. Derivó en corrientes como la Escuela de París (en la que se formaron muchos artistas latinoamericanos), en que el arte nuevo se trabajaba desde una síntesis entre abstracción y figuración que funcionaba como una estilización del Cubismo y se integraba al triunfo internacional del art déco, o bien en tendencias que la llevaban a la ilustración y la propaganda en el marco de cada vez más agudas disputas ideológicas: realismo social, muralismo, regionalismo, etcétera. 
La arquitectura, por su parte, vivió un proceso de institucionalización a través de la organización del Congreso Internacional de Arquitectura Moderna (CIAM) y la consecuente reforma de los programas de enseñanza, a la vez que las políticas nacionalpopulistas ofrecieron la oportunidad de realizar grandes proyectos habitacionales y de obras públicas bajo estos principios. No obstante, este progresivo auge de la arquitectura moderna convive en la década del 30 aún con una serie de lenguajes historicistas y eclécticos, desde el propio art déco hasta diversos estilos "neocoloniales", como también queda graficado al interior de la revista.

\section{Un número dedicado al arte argentino}

Los textos de Estarico y Noel en los cuales se centrará el análisis aparecen en el número 11 de la revista en el año 1936, el que se encuentra dedicado al arte argentino. En el tercer artículo se declara que este número está "dedicado especialmente a las actividades del arte argentino" y que constituye el fruto de una "acción de intercambio cultural" (Sociedad Argentina de Artistas Plásticos 13) iniciada por la Revista de Arte.

Sin embargo, ya desde la imagen de la tapa [Figura 1] se hace referencia a la orientación del número de la revista y también a las tensiones conceptuales sobre las que se instala. Esta corresponde a un detalle del rostro del Monumento al General Alvear, un prócer de la Independencia argentina, realizado por el escultor francés Antoine Bourdelle. En una misma imagen se dan cita el formato tradicional del monumento ecuestre, las formas a la vez sencillas y expresivas de la escultura moderna y el motivo heroico de uno de los próceres de la Independencia argentina y sudamericana. Tradición, modernidad y nación, así podrían resumirse los tres ejes fundamentales en que la Revista de Arte enfocaba sus contenidos.

Una vez abierta la revista, el índice confirma el carácter monográfico de esta edición. Sin contar las secciones estables de la publicación (crónicas y actualidades nacionales y extranjeras, suplemento musical), todos sus artículos se refieren a expresiones artísticas de Argentina o son escritos por intelectuales de dicho país. El arco de temas revisados corresponde al horizonte de la propia revista: artes plásticas, arquitectura y música. El único tópico habitual de la revista del que no se recoge prácticamente ninguna noticia del caso argentino es el de las artes aplicadas. Cabe destacar que varios artículos corresponden a textos ya publicados en aquel país, por lo que se podría inferir que este número de la revista fue el fruto del viaje de alguno de sus editores a Argentina o bien de un intercambio epistolar.

Las páginas de la revista se inauguran con un texto titulado "Un siglo de arte en la Argentina”, firmado por Augusto da Rocha, referido a una exposición del mismo nombre realizada en el Palais de Glace, sede de la Dirección Nacional de Bellas Artes en Buenos Aires, en 1936. Da Rocha era pintor y crítico, y entonces secretario del Museo Nacional de Bellas Artes de Argentina, del que llegaría a ser director. Se 


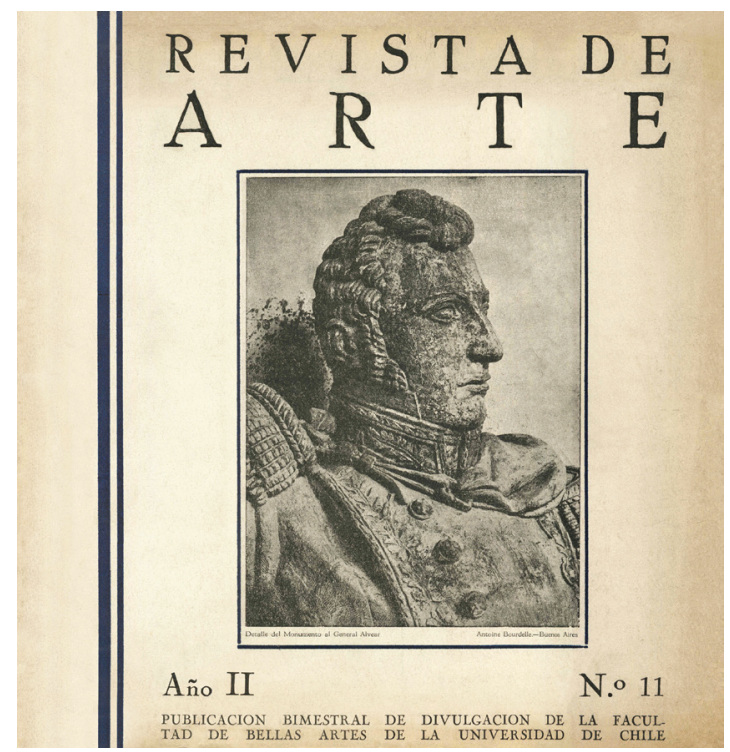

\section{FIGURA 1}

Portada de la Revista de Arte n. ${ }^{\circ} 11$, de 1936.

trataba de una de las más ambiciosas exhibiciones de arte argentino realizadas hasta entonces, con obras de unos cien artistas, entre argentinos y extranjeros residentes, de la cual Da Rocha había participado en su comisión organizadora y, probablemente, ofició como comisario.

Según Da Rocha (1), la muestra constituyó una "feliz comprobación de la existencia de un acervo nativo, paralelo al caudal de influencia extranjera, cuyo aporte valioso fundamenta los orígenes del arte nacional”. Y entre sus enseñanzas, agrega más adelante, está "la posibilidad de encarar seriamente la cuestión de un arte netamente sudamericano, arraigado, no ya en las poderosas corrientes del Viejo Mundo, sino en el primitivo influjo de la tierra y de las antiguas civilizaciones del continente" (2). El autor introduce así una lectura en torno a lo vernáculo, lo nacional y lo americano en relación con el territorio, la que resulta transversal a la época y también a casi todos los artículos de este número de la revista.

En este marco, resulta bastante particular que Da Rocha ubique inequívocamente el apogeo de las artes plásticas argentinas entre los años 1830 y 1860, que coincide con la época del federalismo de Juan Manuel de Rosas, aliado de los caudillos del interior y conocido como "El Restaurador". El autor del artículo parece identificar así a la pampa y al campo argentinos como los territorios desde donde constituir la identidad plástica nacional, y esto parece confirmarlo al abrir su artículo con una reproducción de la pintura Un alto en el campo (1861), de Prilidiano Pueyrredón, con su idílica visión de las costumbres rurales. 
El siguiente artículo se titula "La Sociedad Internacional de Música Contemporánea de Buenos Aires y el 'Grupo Renovación”' y se refiere a la historia, visión y actividades de estas agrupaciones de vanguardia musical. El tercero es una breve reseña de la Sociedad Argentina de Artistas Plásticos y la reproducción de obras y de biografías de algunos de los pintores, escultores y grabadores que la componían, tales como Raquel Forner, Luis Rovatti, Enrique de Larrañaga y Emilio Centurión.

En concordancia con la amplitud de disciplinas abarcada por la revista, el siguiente artículo es el ensayo "La música contemporánea y sus problemas", del musicólogo argentino Leopoldo Hurtado. Se trata de una acuciosa reflexión sociológica acerca del desencuentro entre el público y la música culta y de vanguardia, discusión que continúa en el número siguiente de la revista. Inmediatamente después, sigue el artículo de Leonardo Estarico sobre Pettoruti, que será analizado en detalle.

El brevísimo artículo "Antoine Bourdelle y Sud América" aparece firmado con las iniciales “R. D. D." (1936), que con bastante seguridad corresponden al pintor y escultor Romano de Dominicis, miembro de la comisión directiva de la Revista de Arte y futuro decano de la Facultad de Ciencias y Artes Plásticas. El artículo retoma la relación - que ya se anunciaba en la tapa de la revista - entre Bourdelle, Sudamérica y Argentina, en particular. Luego de entroncarlo en la tradición de un modernismo analítico que lo ubica en la misma senda que Paul Cézanne, afirma que Bourdelle "soñaba para nuestro continente un arte representativo de su medio y de las excepcionales condiciones de su naturaleza" (R. D. D. 31), a pesar de que nunca conoció América. Sin embargo, sus contactos con este continente fueron múltiples, debido a los diversos escultores sudamericanos que estudiaron en su taller: entre ellos el propio De Dominicis, según sugiere el texto, y también José Perotti, artista y figura clave en el desarrollo de las artes aplicadas en Chile (Castillo).

Con Argentina lo unía un nexo particular, pues para este país realizó su Monumento al General Alvear, "que el maestro consideró siempre la más importante de sus obras monumentales" (R. D. D. 31).

Ya introducidos en el contexto de esta publicación y sus orientaciones generales, se analizarán y compararán las visiones que se vierten en los referidos artículos de Estarico y Noel, los dos textos más ambiciosos de esta edición de la revista en lo referido a las artes plásticas y la arquitectura en Argentina, por la articulación conceptual que alcanzan sus hipótesis.

\section{Emilio Pettoruti: una brújula en las fronteras de la plástica}

Leonardo Estarico era un pintor, grabador y crítico de arte argentino que desde la década del veinte ostentaba un importante compromiso con la renovación del arte en su país, especialmente a través de sus textos y de su labor en la gestión de exposiciones de vanguardia. Ya entonces manifestaba un marcado interés por la obra de Pettoruti, 
el que se profundizó cuando a inicios de los treinta se integró a la Agrupación de Artistas Signo, fundada por el propio Pettoruti y el poeta Oliverio Girondo. Entre 1933 y 1934, Estarico llegaría ser el director de esta agrupación en que se daban cita la vanguardia plástica, literaria y musical.

Estarico, en su calidad de militante de la modernización artística, se integra a este número de la Revista de Arte con el artículo titulado "Emilio Pettoruti: brújula de la pintura argentina" (1936). Se trata de un verdadero panegírico cuyas principales alabanzas al pintor se estructuran por medio de metáforas territoriales propias de los textos de vanguardia: brújula, frontera, rumbo, terreno, norte, avance. Las metáforas expresadas por Estarico recuerdan el origen militar del término vanguardia, aludiendo a la posibilidad de que ciertos artistas fueran orientadores en terrenos desconocidos, transgrediendo límites por medio de su práctica artística y definiendo posibles rumbos a seguir por otros artistas. Este es uno de los fundamentos principales que nos llevan a desarrollar el contrapunto entre Estarico y Noel desde la idea de la existencia de un territorio de lo moderno, campo en el que se levantan los argumentos tanto del crítico como del arquitecto.

Estarico afirma que el Pettoruti es un verdadero poeta, en la medida que la poesía sería la "potencialidad de la creación, de invención" y de "emancipación de fórmulas agotadas, cualquiera que sea la especialidad en que se ciernen” (26). Si bien esta reivindicación del pintor como poeta hunde sus raíces en el Renacimiento, en el modernismo de Estarico se actualiza cuando él afirma que Pettoruti era tan poeta como Albert Einstein y Charles Chaplin, pues sostenía que las formas nuevas pueden crearse en cualquier medio.

Para el autor, Pettoruti sería una figura transgresora de fórmulas y cánones “agotados". Por esta razón, el artista sería una brújula de la pintura argentina, en la medida que era capaz de guiarla dentro de las "fronteras de la plástica", establecidas por el paradigma del "arte puro", aunque reconoce que estos límites se actualizan constantemente, como un territorio de bordes inestables. Para Estarico (25), la plástica "vive en vastas geografías que ulterioridades varias modifican día a día".

La plástica, "vocablo revalidado en acepción de actualidad", como introduce el propio Estarico (25), era entonces un término que venía a revolucionar los límites tradicionales de la práctica artística, ampliando y restringiendo su campo de acción. Por un lado, se establecía un vasto territorio en que la pintura, la escultura, la arquitectura, la decoración, las artes aplicadas, e incluso la literatura y la música podían ser comprendidas bajo la idea de la plástica, en la medida que todo arte "se manifiesta por un medio" (28) y que "lo formal es la esencia de toda expresión" (27). Por otro lado, la idea de plástica restringía y establecía fronteras para establecer el territorio que era propio de cada arte y de su medio a través del "estricto sometimiento a lo formal” (27). El contenido quedaba así subordinado a la forma, invirtiéndose los principios de la tradición clásica, para la cual el valor de una obra equivalía al de la historia o anécdota que representaba. Plástica, medio y forma constituyen palabras 
claves de esta lectura modernista del arte que permite a Estarico otorgar un destacado lugar a Pettoruti.

Como buen modernista, Estarico (27) cree que esta visión del arte solo "superficialmente" puede aparecer como una ruptura o "una postura irreverente hacia el pasado". Al contrario, "son un retorno a las leyes, [sic] siempre eternas de la plástica" (27). El autor se refiere a este asunto mientras repasa la controversial exposición que en 1924 realizó Pettorutti en la sala Witcomb, que dividió a la crítica en dos bandos que levantaban sus argumentos a favor o en contra del artista recién llegado de Europa: "Desde 1924, desde Pettoruti, la pintura argentina se aventura en rumbos inéditos" (28). De este modo parece decir que cualquier ruptura que se identifique en este gesto es solo relativa, debido al atraso de Argentina respecto al "ritmo artístico internacional" (26), pues en un sentido absoluto no está haciendo más que reencauzar el arte en su verdadera esencia y tradición: la forma.

Pettoruti sería una ruptura para la pintura argentina solo porque esta no era "pródiga en valores" (Estarico 26). Esta recién se habría comenzado a actualizar con la obra de Martín Malharro, que no iba "más allá de las conquistas del impresionismo" (26), y parecía haberse estancado luego en el "post-impresionismo", gracias a los "cultores de lo fácil, que sólo explotan, imitando lo que otros con esfuerzo alcanzan" (27). Subyace a esta idea un sentido de progreso en el arte, pues "el tiempo anda y todo se supera” (27), de ahí la necesidad de permanente actualización de sus fronteras.

Para Estarico (27), la composición es "la más genuina exteriorización del yo artístico" y "la manifestación sensible de significaciones suprasensibles o no sensibles" (28). En cuanto operación que lleva la forma hacia su manifestación sensible (el medio), la composición sería el fundamento de la plástica. Basado en esta idea de composición es que el autor defiende "lo que ha dado en llamarse el arte abstracto, deshumano" (28), pues constituye una manifestación sensible del pensamiento, "aunque los signos de la escritura sean diferentes de los vulgares" (28). La pintura o la poesía pueden partir de realidades no sensibles, pero siempre "se concreta invariablemente, indefectiblemente, en representación sensible" (28), por lo que toda "gran plástica ha de ser eternamente humana" (28), más allá de los signos con que se escriba.

Al apoyar su argumentación en los polos de lo concreto y lo abstracto, en lo humano y lo deshumano [sic], Estarico toma posición (junto a Pettoruti) en algunos de los debates fundamentales con que se comprendió y discutió el arte nuevo en la época de entreguerras. En particular, muestra un concepto de la plástica moderna como un territorio inestable, cuyas fronteras cambian con los tiempos, al que se puede ingresar en la medida que se tenga una buena guía o brújula, como la que representaría el trabajo de Pettoruti. 


\section{América: territorio e historia ante la nueva arquitectura}

Martín Noel, autor del segundo texto en que se centra este análisis, fue un arquitecto e historiador del arte y la arquitectura de origen argentino. Constituye una de las figuras claves en la valorización y estudio del arte americano del periodo colonial que se desarrolla hacia 1930, dictando en Sevilla, Buenos Aires y Montevideo algunos de los primeros cursos universitarios en esta materia de los que se tenga registro. A su vez, como arquitecto legó una obra también vasta, que incluye residencias privadas, iglesias, hospitales, una embajada y la restauración del Cabildo de Luján. También es autor de algunos de los murales de azulejos de la primera línea del tren subterráneo de Buenos Aires.

El texto de Noel se titula "América y la nueva arquitectura" (1936) y desarrolla la postura del autor ante lo que él considera el mayor dilema estético de su tiempo: la necesidad de conservar una relación creativa con el pasado ante el imparabe triunfo de la técnica y la "revolución de las formas" que de ella se deriva, que pretende "imponer una valla insalvable entre el ayer y el hoy" (33).

Este es el dilema al que se enfrentaría todo el arte y la cultura tras la "Gran Guerra", pero Noel se concentra en lo que implica, particularmente, para la arquitectura. Él afirma que del "triunfo científico y positivo de la técnica imperante" ha nacido "una arquitectura hecha toda de presente" (33). Sin lugar a dudas se refiere a la corriente funcionalista de la arquitectura y el urbanismo modernos, de la que celebra su búsqueda de "bienestar a favor de un mayor número de individuos" (33). No obstante, ve en este movimiento el peligro de entregar al olvido todo lo que la humanidad ha avanzado en "materia constructiva" y de empobrecer la arquitectura por medio de la "frenética tiranía positivista" del funcionalismo (35).

Este dilema presentaría rasgos particulares para América y, especialmente, para "nuestra América" (Noel 33), término que utiliza el autor y que proviene del escritor cubano José Martí. Si bien el texto se refiere a asuntos que afectan a toda América, en concreto analiza la realidad hispanoamericana. En buena medida, Noel se adscribe a la corriente intelectual del hispanismo, que desde la segunda mitad del siglo xix buscaba realzar y recuperar los lazos culturales entre España y sus antiguas colonias, tras un periodo marcado por el rechazo a la tradición cultural de la metrópolis.

En la época de entreguerras fueron muchos los intelectuales y artistas latinoamericanos que adscribieron al hispanismo, estimulados por la búsqueda de fuentes para la identidad americana, por una activa diplomacia cultural española que tuvo su principal hito en la Exposición Iberoamericana de Sevilla en 1929. ${ }^{4}$ A esto se suma la importancia de ciertos intelectuales hispanos del periodo, entre ellos el filósofo José

4 Ver Dümmer (Referencias). 
Ortega y Gasset y el trabajo de divulgación que él mismo ejercía desde la Revista de Occidente y la colección Biblioteca de las Ideas del Siglo xx, donde se tradujeron al español por primera vez algunos textos fundamentales de la corriente formalista en la historia del arte y la arquitectura, como los de Heinrich Wölfflin y Wilhelm Worringer. Americanismo, hispanismo y formalismo constituyen una articulación cultural muy relevante para el periodo, que también se encuentra en la obra de otro de los grandes arquitectos e historiadores la época: el también argentino Ángel Guido.

Según Noel, a América le corresponde, por su "fecundo nativismo y robusta adolescencia, el madurar esa esencia legítima de nuevo mundo en cuyo imponente escenario autóctono las civilizaciones culturales indianas fueron fecundadas por la conquista occidental de la cultura europea" (33-34). No debiera extrañar ni la importancia que se da al territorio americano como fuente de la cultura, ni tampoco la subjetivación de esta, que llega a identificar lo indígena con lo femenino y lo pasivo, y lo europeo con lo masculino y lo activo. En esto Noel sigue al vitalismo alemán de raigambre romántica, pero que en el periodo de entreguerras se actualizaba con figuras como Oswald Spengler, que entonces estaba en boga gracias, entre otros, a los ya citados proyectos editoriales de Ortega y Gasset.

La caracterización vital de la cultura americana entrega a Noel otros argumentos contra el funcionalismo. Además de su carácter femenino y pasivo, América se identificaría con lo nuevo y lo joven, mientras Europa se consideraba una cultura en su ocaso. Para este arquitecto, un corte radical con el pasado, como propondría cierto modernismo, resulta una "postura tanto más grave en un continente cuya exacta gravitación o razón histórica está aún por develar” (35).

En América, entonces, correspondía avanzar volviendo la vista hacia el "espíritu mágico del pasado" (Noel 35). El autor cita al científico e intelectual español Gregorio Marañón, cuando este afirmaba: "No se improvisa una cultura; cuando el caudal está muerto, los artificios no darán nunca el agua cristalina que mana junto a la roca milenaria" (Noel 34). Dentro del mismo paradigma vitalista, la cultura que debe redescubrirse en América es concebida como algo que brota de sus profundidades. Existe, para Noel, una "dimensión tectónica de nuestro continente", que puede notarse en los lugares donde "prevalece ese sentimiento de una cultura autóctona” (35).

Sin embargo, Noel no mira únicamente el pasado nostálgico ni meramente arqueológico. La historia del arte tiene que "dejar de ser una cosa inerte para transformarse en instrumento de creación", afirma el autor (34). "Por el análisis vivo de las fuentes originales", continúa, "saboreamos la emoción estética, de tal suerte que el deleite pasivo se convierte en actividad creadora" (34).

Y especifica aún más las condiciones de este encuentro con el pasado cuando afirma que no es el "detalle anodino y minucioso o el aspecto material y exterior de una composición lo que puede articular la supervivencia de su fuerza medular" (Noel 34). Es decir, no se trata de imitar rasgos iconográficos o estilísticos aislados en un ejercicio de eclecticismo. Lo buscado en el arte y la arquitectura del pasado es su 
"contenido estético cabal, no sólo a título de mero ensueño ideológico, sino en función de un nuevo orden orgánico que se ajuste al espíritu y a la técnica de la época" (34).

Este objetivo se lograría a través de un equilibrio. Debe hacerse "un balance de cuanto es indispensable conservar de un pasado encargado de vincular todo ciclo vital al concepto de interpretación del universo" (Noel 34). Y, al mismo tiempo, hay que "cristalizar las conquistas técnicas de nuestro siglo dentro de soluciones capaces de satisfacer las exigencias económicas de un nuevo programa social” (34). Esa es la solución al dilema que Noel observa en su época al pleito ideológico entre la orientación hacia lo material y lo inmaterial, que equipara a una confrontación entre "Romanticismo y Maquinismo", tal como ha existido la confrontación entre "Clasicismo y Barroquismo" y "Racionalismo y Misticismo" (34), en lo que parece una referencia a los pares polares definidos por Wölfflin.

Encontrar el equilibrio aludido permite hallar en la tradición la "matriz de la belleza jerárquica que ha de permitirnos el atar los cabos entre el pasado y el porvenir" (Noel 34). Para el autor, se debe responder a las nuevas condiciones históricas "observando [...] los principios establecidos por la verdad y la belleza" (35), lo que nos confirma la raíz clásica de sus valores estéticos.

Este arquitecto configura así un verdadero nacionalismo estético, entre tantos que proliferaron como un contrapunto al avance del funcionalismo, desde la reacción contra la arquitectura racionalista en la Alemania nazi hasta la "restauración nacionalista" propuesta por el intelectual argentino Ricardo Rojas en la primera década del siglo xx. Noel (35) ve en la "sobria belleza de la cultura 'ibero-andina" la posibilidad de encontrar "el resorte medular de una nueva arquitectura". Una tradición que surge en la península Ibérica, donde ha decantado la cultura del Mediterráneo, para luego fecundar en América y surgir plena en las "urbes virreinales", "espaldeadas en los arcaísmos indígenas" (35).

El propio autor entrega como ejemplo de una relación viva con esta historia la emergencia del estilo californiano en Estados Unidos, que no sería otra cosa que el "andalucismo americanizado en Méjico" o el "escueto barroquismo misionero" (35). Un ejemplo resulta clave para entender de forma más concreta la propuesta de Noel. Al finalizar su artículo, la revista dedica una página completa a reproducir una fotografía de la Casa Portada Colonial [Figura 2], diseñada y construida por este arquitecto en Santiago en 1926 y ubicada en la intersección de las calles Merced e Irene Morales, frente al Parque Forestal en el centro de la capital.

El historiador de la arquitectura Pablo Fuentes la describe como sigue:

posee una manifiesta influencia renacentista española que recuerda la arquitectura ubetense de Andrés de Vandelvira. Es un cuerpo de tres niveles con paramentos lisos que rematan en su parte superior con una delgada cornisa. Sus vanos apenas aparecen decorados con bordes y frontispicios. La fachada con mayor desarrollo por la última calle se muestra flanqueada por dos torres. Se trata de una fachada densa y compacta con pocos vanos. En su centro, arriba, ventanas 
en arco se asimilan a una logia y rematan el edificio. La torre cuadrada esquina, más alta y la más característica, tiene lecturas diferentes por cada planta. En el primer nivel un arco de medio punto se dobla en dos para cobijar bajo él un ochavo en $45^{\circ}$. En el segundo se dispone una ventana a cada lado con balcón metálico. En el tercer piso su ventana esquinada con mainel y coronada con un escudo caracteriza la composición (144-145).

Con todas estas características, la casa corresponde a una solución posible dentro de las que contemplaba el estilo neocolonial, que se desarrolla en América Latina durante los veinte y los treinta, pero que seguirá teniendo una importante influencia, como lo prueba el llamado Plan Serena en Chile. A partir de este proyecto se construyeron entre 1948 y 1952 una serie de edificios públicos en estilo neocolonial en la ciudad de La Serena, principalmente, que constituyen hasta hoy la principal identidad estilítica de esta urbe.

\section{FIGURA 2}

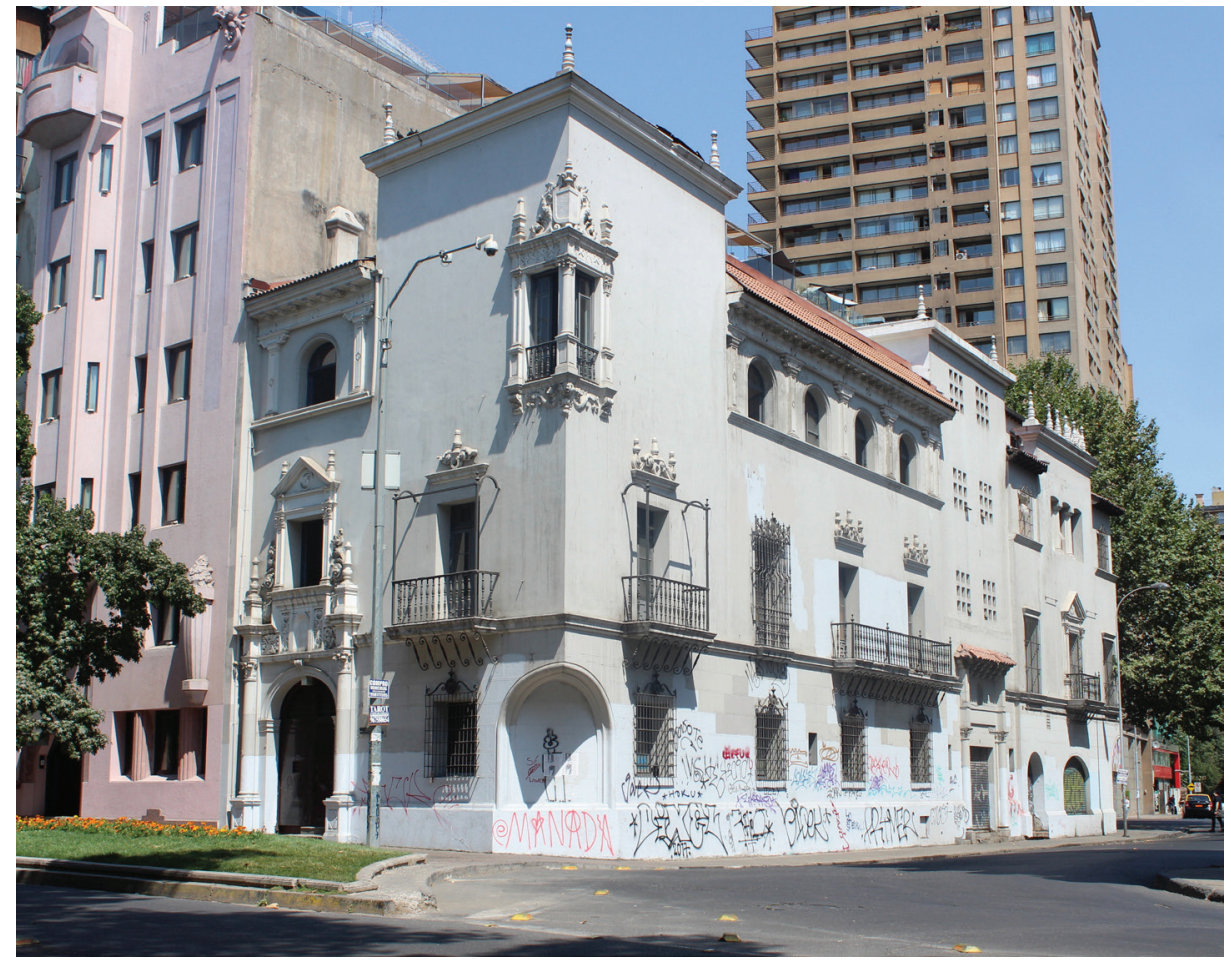

Casa Portada Colonial (1926), obra de Martín Noel ubicada en la intersección de calle Merced con Irene Morales, Santiago.

Fotografía: Micchela Messone W. 
MUSEO NACIONAL DE BELLAS ARTES

EXPOSICION RETROSPEGTIVA DE LA OBRA DEL PINTOR



\section{E M I L I O P ET TOR U T I}

A GOSTO DE 1950

SA N T A G O - CH I L E

FIGURA 3

Catálogo de la exposición retrospectiva de Emilio Pettoruti en el Museo Nacional de Bellas Artes de Santiago. Agosto de 1950. 
Resulta curioso que la propuesta de Noel se desmarque de la mayoría de los artículos de arquitectura de la Revista de Arte. Sin tener una línea establecida, la gran mayoría de ellos resultan bastante vanguardistas y se aproximan al funcionalismo, como un reflejo de la importante renovación de la arquitectura que se suscitaba en Chile. Tal vez, el único texto que se acerca a la línea de Noel, se dedica a la arquitectura barroca "Hispano-Aborigen" y al Cuzco en el número 9 de la revista, dedicado al arte peruano.

Sin embargo, la sección de arquitectura de la misma publicación llevaba tres números publicando un largo estudio sobre la vivienda obrera en Inglaterra, de marcado tinte funcionalista. En la misma edición 11 de la Revista de Arte, el artículo de Noel comparte sus páginas con un texto titulado "La vivienda popular en su aspecto plástico y arquitectónico integral”, del arquitecto chileno Luis Muñoz Maluschka, que desde el título se acerca a la idea de plástica con que Estarico se refería a la obra de Pettoruti. En lo rigurosamente arquitectónico, prioriza el "aspecto funcionalista, material, económico y financiero y aun en el urbanístico comprendido en su finalidad práctica de organización de conjuntos de viviendas adaptadas a una necesidad económica social" (Muñoz 38), en contraste con "el problema de la expresión arquitectónica individual y colectiva de la vivienda popular", que relega a un segundo término (38).

\section{Conclusiones}

La aparente contradicción editorial que supone la yuxtaposición de posturas tan diferentes en torno a lo moderno bien refleja las discordancias del campo cultural de la época de entreguerras en Chile, Argentina y, muy probablemente, en el resto de América Latina. Es cierto que el artículo de Estarico parece más vanguardista que la mayoría de los artículos sobre pintura publicados en la Revista de Arte, así como el de Noel podría parecer más conservador que el resto de los aparecidos sobre arquitectura. Sin embargo, hacer esta distinción no resulta tan sencillo cuando se observan, además de los elementos que los distancian, los principios que ambos textos comparten.

En primer lugar, ambos estructuran sus lecturas de lo moderno, del dilema de su tiempo, desde metáforas y referencias territoriales. Mientras Estarico utiliza términos como frontera, brújula o avance para ubicarse en un territorio de carácter universal y cambiante, como sería el de la plástica, Noel asume que el desafío de su tiempo consiste en que la nueva arquitectura americana debe orientarse hacia su territorio autóctono y su historia.

En segundo lugar, ambos suponen que el arte o la arquitectura deben lograrse en un equilibrio entre la creación y la tradición. Estarico, por una parte, recupera la idea del artista como creador y poeta que tiene raíz en la teoría del arte renacentista y se renueva en el periodo de la vanguardia. Para él, la creación verdadera no consiste en los "simiescos remedos" de los "pseudos innovadores" (27) ni tampoco significa 
romper con el pasado pues, al contrario, constituye un retorno a las leyes eternas de la plástica. Noel, por otra parte, enfatiza la importancia de la creación y la belleza para "no rendirse automáticamente a lo mecánico" (35) y hace un sentido llamado a reencontrarse con la tradición americana para hallar las fuentes de ambos valores.

En Chile, la figura de Pettoruti crecerá en importancia con los años, a tal punto que en 1950 el Museo Nacional de Bellas Artes organizó una amplia retrospectiva de su obra, la que hoy es considerada un hito en la progresiva formación de una vanguardia abstracto-geométrica en la escena local. Cabe destacar que el historiador y crítico de arte argentino Julio Payró, en el catálogo de la muestra [Figura 3], definió a Pettoruti y su obra en términos muy similares a los que utilizó Estarico en los años treinta: "Creador: tal la palabra exacta. Pues su arte se mantiene desdeñosamente alejado de todo recurso de imitación” (Payró 10).

El nacionalismo estético que proponía Noel con su defensa de un estilo neocolonial seguirá presente hasta mediados de la década de 1950, pues todavía se encontrarán grandes edificaciones de estilos historicistas y algunas específicamente americanistas y neocoloniales, como los construidos gracias al ya nombrado Plan Serena. Sin embargo, hacia 1960 esta corriente va a fundirse y luego desaparecer con las oleadas del movimiento moderno, el que tendería a hegemonizar la arquitectura de avanzada en el medio local hacia 1960.

\section{Referencias}

Berríos, Pablo, Eva Cancino y Kaliuska Santibañez. La construcción de lo contemporáneo. La institución moderna del arte en Chile (1910-1947). Santiago, Estudios de Arte - Departamento de Teoría de las Artes, Universidad de Chile, 2012.

Castillo, Eduardo. Artesanos, artistas, artífices. La Escuela de Artes Aplicadas de la Universidad de Chile 1928-1968. Santiago, Ocho Libros, 2010.

Da Rocha, Augusto. "Un siglo de arte en la Argentina”. Revista de Arte, n. ${ }^{0} 11,1936$, pp. 1-5.

Dümmer, Sylvia. Sin tropicalismos ni exageraciones. La construcción de la imagen de Chile para la Exposición Iberoamericana de Sevilla en 1929. Santiago, Instituto de Historia, Pontificia Universidad Católica de Chile / RIL Editores, 2012.

Estarico, Leonardo. "Emilio Pettoruti: brújula de la pintura argentina”. Revista de Arte, n. ${ }^{\circ} 11,1936$, pp. $25-28$.

Fuentes, Pablo. Antecedentes de la arquitectura moderna en Chile (1894-1929). Concepción, Ediciones Universidad del Bío-Bío, 2009.

Gutiérrez, Ramón. Arquitectura y urbanismo en Iberoamérica. Madrid, Cátedra, 1997. Muñoz, Luis. "La vivienda popular en su aspecto plástico y arquitectónico integral". Revista de Arte, n. ${ }^{\circ} 11,1936$, pp. 38-39.

Noel, Martín. “América y la nueva arquitectura”. Revista de Arte, n. o 11, 1936, pp. 33-36. 
Payró, Julio. "El pintor Emilio Pettoruti". Exposición retrospectiva de la obra del pintor Emilio Pettoruti. Santiago, Museo Nacional de Bellas Artes - Editorial Universitaria, 1950, pp. 5-11.

R. D. D. [Romano de Dominicis]. "Antoine Bourdelle y Sud América”. Revista de Arte, n. ${ }^{\circ} 11,1936$, p. 31.

Rojas Mix, Miguel. "Revista de Arte, publicación bimestral de la Facultad de Bellas Artes de la Universidad de Chile”. América. Cahiers du CRICCAL, n. ${ }^{\circ}$ 4-5, 1990, pp. 477-485.

“Sociedad Argentina de Artistas Plásticos". Revista de Arte, n. 11, 1936, pp. 13-18.

Enviado: 10 de enero de 2019

Aceptado: 20 de enero de 2020 